\title{
Gestão de recursos financeiros da educação permanente em saúde: desafio das comissões de integração ensino-serviço
}

\author{
Management of financial resources of permament education \\ in health: challenge of the in-service learning integration committees
}

Fabiane Ferraz ${ }^{1}$

Vânia Marli Schubert Backes ${ }^{1}$

Francisco Javier Mercado-Martinez ${ }^{2}$

Laura Camargo Macruz Feuerwerker ${ }^{3}$

Mônica Motta Lino

${ }^{1}$ Grupo de Pesquisa em Educação em Enfermagem e Saúde - EDEN/PEN.

Universidade Federal de Santa Catarina. Campus Universitário Reitor João David Ferreira Lima Centro de Ciências da Saúde, Trindade. 88040-970 Florianopolis SC. olaferraz@gmail.com

${ }^{2}$ Universidade de

Guadalajara.

${ }^{3}$ Faculdade de Saúde Pública, Universidade de São Paulo.

\begin{abstract}
Despite adhering to the dynamics established in the Management Pact, the use of financial resources of Permanent Education in Health (PEH) still features as a problem in Brazil. This study analyzes how the management of these financial resources by two Permanent In-Service Learning Integration Committees (ICLS) evolves in the State of Santa Catarina, Brazil. It involves a qualitative, participatory research study adapted from Paulo Freire's Thematic Research conducted with 56 members from two ICLS between May and December 2009. After setting up the research groups, the members participated in the stages of theme generation surveys, encoding, decoding, and critical exposition of the reality. Participant observation and dialogue were the main data collection techniques. The results indicate that the two ICLS are not dissimilar in terms of issues of management of resources destined for policy, with bureaucracy, the indefinition of forms of $f i$ nancial management and delays that permeate regional structures responsible for resource management being the main factors detected. The participants considered the elaboration of PEH actions in the management of financial resources at state level to be the main opportunities for change. Key words Ongoing Education, Unified Health System, Health Financing
\end{abstract}

Resumo A utilização dos recursos financeiros da educação permanente em saúde (EPS) no Brasil, mesmo seguindo a dinâmica estabelecida no Pacto de Gestão, ainda configura-se como um problema nesse contexto. O objetivo foi analisar como ocorre a gestão dos recursos financeiros da Política Nacional de Educação Permanente em duas Comissões Permanentes de Integração Ensino-Serviço (CIES), em Santa Catarina. Estudo qualitativo, do tipo pesquisa participante, realizado através da adequação da Investigação Temática de Paulo Freire, de maio-dezembro/2009, com 56 membros de duas CIES que, após a formação de círculos de investigação, participaram das etapas: levantamento dos temas geradores, codificação, decodificação e desvelamento crítico da realidade. A observação participante e o diálogo foram as principais técnicas de coleta de informações. Os resultados indicam que as CIES se assemelham nas problemáticas relacionadas à gestão de recursos destinados à política, sendo a burocratização, $a$ indefinição de formas de gestão financeira e a morosidade que permeiam as estruturas regionais responsáveis pela gestão dos recursos são os principais fatores explicitados. Os participantes apresentam como possibilidades de mudança a elaboração de ações de EPS sobre a gestão de recursos financeiros em nivel estadual.

Palavras-chave Educação continuada, Sistema Único de Saúde, Financiamento em saúde 


\section{Introdução}

Tendo em vista o princípio da descentralização, desde os anos 90 do século XX, o Sistema Único de Saúde (SUS) criou mecanismos para facilitar a transferência de recursos entre os entes federados para o financiamento das ações e serviços de saúde no Brasil. Mais recentemente o Pacto de Gestão (2006) criou cinco "blocos" para a transferência de recursos fundo-a-fundo, quais sejam: Atenção Básica; Atenção de Média e Alta Complexidade Ambulatorial e Hospitalar; Vigilância em Saúde; Assistência Farmacêutica; e Gestão do SUS.

Em consonância com o Pacto de Gestão, a Política Nacional de Educação Permanente em Saúde (PNEPS), instituída no Brasil em 2004, teve suas estratégias de ação e transferência de recursos para financiamento das ações redefinidas pela Portaria GM/MS no 1.996/07¹. Esta estabeleceu a transferência regular e automática dos recursos para Educação Permanente em Saúde (EPS) do Fundo Nacional de Saúde aos respectivos Fundos Estaduais ou Municipais de Saúde, dentro do "bloco de Gestão do SUS". Teoricamente, esse mecanismo de repasse aplica-se somente às regiões que aderiram ao Pacto de Gestão². Ainda, a condução da PNEPS, também foi redefinida pela portaria e, atualmente, ocorre por meio das Comissões Intergestores Regionais (CIR) - que antes da promulgação do Decreto $n^{\circ} 7.508 / 11^{3}$ eram denominadas como Colegiados de Gestão Regional (CGR) - com a participação das Comissões Permanentes de Integração Ensino-Serviço (CIES), detalhados no Quadro1.

A descentralização prevista na estruturação do SUS tem sido um grande desafio. Por um lado, possibilita aproximar a construção do sistema das diferentes realidades locais, havendo "um certo grau de autonomia" para os gestores locais na elaboração de políticas específicas, visto que ainda persiste no SUS um modo centralizado de formulação e proposição de políticas, sendo assim, efetivamente a municipalização possibilitou levar a agenda da saúde para a totalidade dos municípios brasileiros. No entanto, essa descentralização ocorreu sem que houvesse um investimento efetivo na qualificação da gestão local - não somente por meio de "capacitações", mas através do

Quadro 1. Estrutura regional do processo de Educação Permanente em Saúde, segundo diretrizes operacionais e Pacto de Gestão.

\begin{tabular}{|l|l|}
\hline \multicolumn{2}{|c|}{ Comissão Intergestores Regional (CIR)* } \\
\hline $\begin{array}{l}\text { Composição } \\
\begin{array}{l}\text { Gestores municipais de saúde do conjunto de } \\
\text { municípios de uma determinada região de saúde e } \\
\text { por representantes do(s) gestor(es) estadual(ais). }\end{array}\end{array}$ & $\begin{array}{l}\text { Anstituir processo de planejamento regional para a } \\
\text { Edução Permanente em Saúde, que defina as } \\
\text { prioridades, as responsabilidades de cada ente e o } \\
\text { apoio para o processo de planejamento local, } \\
\text { conforme as responsabilidades assumidas nos Termos } \\
\text { de Compromissos e os Planos de Saúde dos entes } \\
\text { federados participantes. }\end{array}$ \\
\hline \multicolumn{2}{|c|}{ Comissão Permanente de Integração Ensino-Serviços (CIES) } \\
\hline $\begin{array}{l}\text { Composição } \\
\begin{array}{l}\text { Gestores municipais e estaduais de saúde e } \\
\text { educação e/ou seus representantes Trabalhadores do } \\
\text { SUS e/ou entidades representativas Instituições de } \\
\text { ensino com cursos na área da saúde por meio de } \\
\text { seus distintos segmentosMovimentos sociais ligados } \\
\text { à gestão das políticas públicas de saúde e do controle } \\
\text { social no SUS }\end{array}\end{array}$ & $\begin{array}{l}\text { Atribuição } \\
\text { Propor, elaborar, monitorar e avaliar os projetos de } \\
\text { Colegiado de Gestão Regional que possam orientar } \\
\text { suas decisões em relação ao Plano de Ação Regional } \\
\text { de Educação Permanente em Saúde (PAREPS). }\end{array}$ \\
\hline
\end{tabular}

Fonte: Política Nacional de Educação Permanente em Saúde, Brasil, 2009.

* Com a promulgação do Decreto n. 7.508, de 28 de junho de 2011, que regulamente a Lei n. 8.080, de 19 de setembro de 1990, para dispor sobre a organização do Sistema Único de Saúde - SUS, o planejamento da saúde, a assistência à saúde e a articulação interfederativa, e dá outras providências. O antigo Colegiado de Gestão Regional (CGR) passou a ser denominado como

"Comissão Intergestores Regional (CIR)"3. 
apoio efetivo, direto, presencial, à construção da caixa de ferramentas das equipes locais para a gestão e para a formulação de políticas ${ }^{4}$.

Considerando que $70 \%$ dos municípios brasileiros têm menos de 20 mil habitantes e que apenas pouco mais de 300 têm mais de $100 \mathrm{mil}$ habitantes, fica fácil compreender a importância dessa ação de apoio efetivo. Sem esse aporte, apenas um número limitado de municípios conseguiu construir um "corpo de gestão" com efetiva capacidade propositiva. As consequências se fazem visíveis em diversos âmbitos do sistema, fragilizados diante da limitada capacidade local de formular soluções específicas para suas respectivas realidades 5 .

Essas dificuldades se manifestam na gestão de processos de educação permanente em saúde. Sendo que, em especial, a do financiamento já era um dos elementos identificados como fragilidade nos Polos de Educação Permanente em Saúde - estratégia anterior da PNPES. Na época, diante da limitada participação dos municípios na identificação de necessidades e na construção de estratégias para a EPS, outros sujeitos adquiriram protagonismo - o que gerou desconforto, pois muitas vezes os projetos apresentados aos Polos não eram estruturados a partir das necessidades locais dos serviços/comunidades, mas sim eram aprovadas propostas pré-elaboradas nas Instituições de Ensino Superior (IES) sem a articulação necessária junto às realidades locais ${ }^{6}$. Este segue sendo um fator limitante para a produção de políticas regionais de educação permanente em saúde em âmbito de algumas CIR e CIES ${ }^{2,6,7}$.

Nesse cenário, o Estado de Santa Catarina (SC), atendendo ao Plano Diretor de Regionalização de 2002 (PDR/2002), ao Pacto de Gestão do SUS e a Portaria GM/MS No 1.996/2007, instituiu 15 Colegiados de Gestão Regional - atualmente denominados de Comissões Intergestores Regional - e, 15 Comissões Permanentes de Integração Ensino-Serviço, que abrangem todos os municípios do Estado. Esse desenho foi alterado em 2009 a partir de uma revisão estrutural passando a funcionar 16 CIR (antigos CGR) e 16 CIES $^{8,9}$.

Ainda em Santa Catarina, a coordenação estadual da PNEPS ocorre por meio da Divisão de Educação Permanente (DEP), subordinada à Diretoria de Educação Permanente em Saúde (DEPS), da Secretaria de Estado da Saúde (SES). A DEP articula a política junto a outras estruturas administrativas estaduais e ao MS, presta assessoria direta as 16 CIES, conduz a elaboração e a execução das ações de EPS propostas no Plano Estadual de Educação Permanente em Saú- de. Seu coordenador, entre outras funções, é o secretário da CIES Estadual implantada em 2010.

Desde 2004, a PNEPS preconiza que os sujeitos sociais, representantes dos segmentos de ensino, gestão, atenção e controle social - que compõem a CIES - vivenciem ativamente o processo de construção e efetivação da política ${ }^{10}$. Assim, é fundamental que os membros das CIES conheçam o processo de gestão, organização e estruturação da PNEPS em âmbito regional, a fim de serem capazes de materializá-la.

Este estudo teve por objetivo analisar como ocorre a gestão dos recursos financeiros da Política Nacional de Educação Permanente em duas Comissões Permanente de Integração EnsinoServiço, no Estado de Santa Catarina, Brasil.

A gestão regional da PNEPS envolve não somente as CIES, mas também as CIR. No entanto, optamos por analisar as primeiras pelo fato de serem instâncias articuladoras dos diferentes segmentos que participam da construção do SUS, sendo responsáveis pela formulação, condução e desenvolvimento das ações de EPS em nível local ${ }^{2}$.

As ações de EPS estão baseadas em referenciais participativos, segundo os quais os sujeitos sociais devem ser ativos na construção de propostas que favoreçam a problematização do cotidiano do trabalho e da formação em saúde ${ }^{11}$. A reflexão sobre o processo de trabalho em saúde, produzida de modo dialógico, coletivo e inclusivo, é pressuposto para a possibilidade de transformação da realidade em questão por meio da práxis. Devido a isso, a presente investigação, estruturada à luz do referencial teórico-metodológico de Paulo Freire ${ }^{12-14}$, não tem a pretensão de comparações, pois busca discutir as potencialidades e as fragilidades vivenciadas em cada CIES, bem como destacar a forma como os participantes dialogicamente se organizam para buscar soluções aos problemas do manejo dos recursos financeiros da EPS.

\section{Metodologia}

Estudo qualitativo, do tipo pesquisa participan$\mathrm{te}^{15}$, desenvolvido por meio de uma "adequação" da Investigação Temática (IT) elaborada por Paulo Freire. A IT se estrutura a partir da relação dialógica entre os seres humanos, sendo que não há como manter esta relação sem considerar o contexto histórico, político, econômico, social e cultural, ou seja, o "mundo" dos sujeitos participantes do Círculo de Investigação, pois a Investigação Temática ocorre no “domínio do humano 
e não no das coisas, não pode reduzir-se a um ato mecânico. Sendo processo de busca de conhecimento, por isto tudo, de criação, exige de seus sujeitos que vão descobrindo, no encantamento dos temas significativos, a interpenetração dos problemas"12-14.

A Investigação Temática foi realizada de maio a dezembro de 2009, em duas CIES do Estado de Santa Catarina, Brasil e iniciou com a composição dos Círculos de Investigação Temática e foi estruturada em três etapas articuladas ao longo do trabalho de campo: a) Levantamento dos Temas Geradores; b) Codificação; e c) Decodificação e Desvelamento Crítico da Realidade ${ }^{12-14}$.

A CIES Grande Florianópolis: estruturada pela CIR da Grande Florianópolis, em junho de 2008 - composta, no início da investigação, por 11 membros titulares representantes dos segmentos de serviço, ensino, gestão e controle social, com secretaria executiva estruturada junto a Escola de Formação em Saúde (EFOS). Essa CIES pertence à Região Grande Florianópolis, composta por 22 municípios. O arranjo administrativo do Estado, por ter diferentes estruturas de divisão das regiões de saúde, as quais historicamente foram sendo constituídas sem haver uma coerência interna entre si, define que a $18^{\text {a Secre- }}$ taria de Estado de Desenvolvimento Regional (SDR) atenda a maioria (13) dos municípios da região, sendo considerada pela CIR a referência para assuntos administrativos junto à SES. A CIES Carbonífera: pertence à Região Carbonífera composta, no período do estudo, por 11 municípios da Região Sul de Santa Catarina, que tem como referência administrativa a $21^{\text {a }}$ SDR. No início da pesquisa, a CIES possuía 21 membros titulares, e sua composição abrangia os segmentos de serviço, ensino, gestão e controle social. A secretaria executiva estava estruturada junto à 21 a Gerência Regional de Saúde (GERSA), estabelecida desde a época da primeira fase da PNEPS.

As CIES foram escolhidas intencionalmente, em virtude de facilidades logísticas para a pesquisadora-mediadora efetivar o acompanhamento e registro das ações. A coleta de informações iniciou com a formação de um Círculo de Investigação em cada CIES, o que implicou a participação da pesquisadora-mediadora em 16 e 17 reuniões de trabalho das CIES Grande Florianópolis e Carbonífera, respectivamente. As etapas da IT foram implementadas em 5 reuniões na CIES Grande Florianópolis e em 6 na CIES Carbonífera nas quais a investigação foi ponto de pauta, com duração de $1 \mathrm{~h}$ a $3 \mathrm{~h}$ por encontro.
Os sujeitos da pesquisa foram os membros titulares e suplentes representantes do ensino, gestão, serviços e controle social, configurandose 21 participantes da CIES Grande Florianópolis e 35 da CIES Carbonífera. Suas participações variaram entre as reuniões de trabalho e a realização da IT propriamente dita. Nos encontros específicos da IT, participaram de 7 a 15 membros na CIES Florianópolis e de 10 a 17 sujeitos na CIES Carbonífera.

Ao longo da Investigação Temática, foi realizada a triangulação de técnicas para obtenção das informações, utilizando-se principalmente de observação participante e diálogo entre os membros dos círculos a partir de perguntas instigadoras. Essas sessões foram registradas por meio de cadernos de campo, reorganizados após cada observação em documentos específicos no Microsoft Word ${ }^{\circledR}$ e revisados de modo a assegurar a máxima fidedignidade na descrição dos aspectos observados.

Sempre que autorizado pelos participantes, as reuniões de trabalho e as etapas da IT foram gravadas em arquivo digital e posteriormente transcritas. Os depoimentos eram compilados juntamente com as descrições para serem devolvidos aos círculos no processo da investigação. Os registros subjetivos fomentavam os questionamentos que a pesquisadora-mediadora realizava ao longo das etapas dos círculos de investigação para estimular o diálogo e a reflexão sobre a realidade vivida pelos participantes.

Ao longo das etapas específicas de IT $^{12-14}$, utilizamos também diferentes dinâmicas para composição do "corpus de dados" da investigação:

1) Levantamento dos temas geradores: os registros objetivos das reuniões de trabalho e da formação dos círculos de investigação foram apresentados de forma escrita aos participantes dos círculos. Os membros se dividiram em subcírculos conforme presença nas reuniões anteriores das CIES para leitura dos registros, destacando aspectos que lhes causavam desconforto e incômodo, denominados de "situações-limite" que estão intrinsecamente ligadas aos "temas geradores” ${ }^{14}$. Após discussão e análise do material, os participantes formavam novamente o círculo de investigação e dialogavam acerca dos aspectos destacados como temas geradores pelos subcírculos. O diálogo no círculo de investigação permitiu a emersão de novos temas geradores e novas situações-limites.

2) Codificação: as duas CIES validaram uma lista de temas geradores, sendo apresentados neste 
estudo apenas os referentes à gestão de recursos financeiros da PNEPS, que são: "indefinição de mecanismos burocráticos legais de utilização dos recursos financeiros destinados às ações de EPS propostas pela CIES, bem como dos valores destinados especificamente para a manutenção da CIES" (CIES Grande Florianópolis) e "dificuldade de gestão dos recursos da PNEPS destinados às ações de EPS elaboradas pela CIES" (CIES Carbonífera). Desenvolvemos, ainda, uma técnica projetiva com a qual apresentamos às CIES um painel com as informações codificadas de cada realidade, elaborada a partir dos temas geradores validados, da organização das informações extraídas das observações participantes e das gravações das reuniões de trabalho. Os painéis foram discutidos em subcírculos e, ao final, entre todos os membros dos círculos de IT das CIES, evidenciando a compreensão dos participantes sobre os temas geradores que emergiram em cada realidade.

3) Decodificação e Desvelamento crítico da realidade: devido ao caráter dinâmico da metodologia, a decodificação aconteceu de modo articulado à codificação em ambas as CIES, pois, inicialmente, os participantes descreveram os aspectos vivenciados a partir da sua própria identificação na projeção apresentada nos painéis, para logo refletirem sobre eles a partir de outro ponto de vista. Assim, o desvelamento crítico teve início no momento em que os participantes posicionaram-se de modo crítico a respeito dos temas geradores, havendo um movimento de mudança em relação à descrição inicial da situação.

A análise qualitativa dos dados ocorreu concomitante à coleta. Quando os temas geradores foram codificados, apresentados e rediscutidos pelos membros dos círculos de investigação das CIES, emergiram temáticas que passaram por um processo de análise coletiva e movimento de mudança em diferentes dimensões ${ }^{15,16}$. Os resultados foram analisados e estruturados ao longo das etapas da IT e, no processo final de análise, fez-se a compilação dos temas geradores de modo a compor a grande temática sobre a "gestão dos recursos financeiros da PNEPS destinados as CIES”, bem como uma discussão teórica, que possibilitou o diálogo com outros autores. Este estudo foi aprovado no Comitê de Ética em Pesquisa com Seres Humanos da SES/SC, atendendo aos critérios da Resolução do CNS no 196/ $96^{17}$. As identidades dos participantes estão preservadas por pseudônimos escolhidos por eles próprios.

\section{Resultados e discussão}

\section{O contexto}

A partir do Pacto de Gestão, em 2008 se concretizou a mudança da dinâmica de financiamento da política de EPS. O ano de 2009, período de realização da Investigação Temática foi, portanto, um ano desafiador permeado por dúvidas, dificuldades e incertezas explicitadas nos itens a seguir descritos no presente estudo:

a) no início da investigação, em 2009, a maior parte dos recursos de 2007 e 2008, transferidos do Fundo Nacional de Saúde ao Fundo Estadual de Saúde de Santa Catarina para EPS, ainda se encontrava no Fundo Estadual. Durante o ano de 2008, as CIES estavam se estruturando na maioria das regiões do Estado e apenas três regiões conseguiram descentralizar o recurso de 2007. As demais CIES, inclusive as participantes deste estudo, efetivaram esse movimento no ano de 2009;

b) por orientação da Diretoria Geral da SES/ SC, o recurso deveria, preferencialmente, ser repassado do Fundo Estadual de Saúde às CIES regionais por meio de: 1 ) descentralização de crédito para as Secretarias de Estado de Desenvolvimento Regionais (SDR); ou, 2) transferência fundo-a-fundo do Fundo Estadual ao Fundo Municipal de Saúde de algum município das CIES;

c) as CIR, as quais se articulam as CIES Grande Florianópolis e Carbonífera, optaram pela descentralização de crédito para as Secretarias de Estado de Desenvolvimento Regionais (SDR). Desse modo, os recursos dos anos de 2007-2008 da CIES Carbonífera foram transferidos em julho de 2009 para a 21. SDR, e o recurso da CIES Grande Florianópolis referente aos anos 20072008 foi transferido em outubro de 2009 para a $18^{\mathrm{a}} \mathrm{SDR}$;

d) a definição orçamentária do valor repassado do Fundo Estadual de Saúde para as 16 CIES regionais seguiu o disposto na Deliberação n ${ }^{\circ} 248 /$ $\mathrm{CIB} / 08^{18}$, que se baseou nos critérios de alocação orçamentária apresentados no Anexo I da Portaria GM/MS no $1.996 / 07^{1}$. Ainda, segundo a mesma deliberação, 10\% do montante dos recursos da PNEPS referentes a 2008 ficam retidos no Fundo Estadual de Saúde para manutenção do Fórum de Educação Permanente em Saúde (atual CIES Estadual) e desenvolvimento de ações de EPS em âmbito estadual, atualmente previstas no Plano Estadual de Educação Permanente em Saúde. A mesma determinação valeria para o recurso 2009 quando fosse transferido pela União, sendo 
que os recursos são repassados da União para os Estados ao final do ano corrente. Logo, o recurso de um ano é utilizado no ano seguinte, por exemplo, o recurso da PNEPS de 2008 foi transferido para o Fundo Estadual de Saúde de Santa Catarina em dezembro de 2008 e só pode ser repassado às CIES regionais em 2009.

\section{A gestão dos recursos}

No Quadro 2, encontram-se os principais aspectos relacionados à dificuldade de gestão dos recursos, sobre os quais se dialogou nos círculos de IT.

Em um estudo sobre a estratégia anterior de efetivação da PNEPS (Polos de EPS), as dificuldades mais comuns para a utilização de recursos financeiros da educação permanente em saúde referiam-se a disponibilidade dos recursos (atrasos e insuficiência), necessidade de infraestrutura (instalações e equipamentos), dúvidas acerca da gestão financeira e receio de que a instância de articulação fosse considerada apenas uma intermediária financeira de projetos ${ }^{6}$. Apesar do grande avanço representado pela adoção do mecanismo de transferência fundo-a-fundo dos recursos da Portaria GM/MS no $1.996 / 07^{1}$, algumas dificuldades se mantiveram. Persistem dúvidas acerca da gestão financeira, particularmente sobre a contratação de serviços na área de educação, mais especificamente em relação à Instrução Normativa do Tribunal de Contas da União, que impede a remuneração de funcionários públicos nas atividades de EPS. Isso faz com que seja necessário ter um "intermediador", ou para o repasse dos recursos, ou para a efetivação das ações.

Conforme pode ser constatado no Quadro 2 , as dificuldades expressas anteriormente foram apresentadas como temas geradores pelos sujeitos dos círculos de IT. Embora a dificuldade de utilização dos recursos seja motivada pela referida instrução normativa, no processo de discussão estabelecido no interior dos círculos de IT, a dificuldade foi referida a "problemas com a lei de Responsabilidade Fiscal”, provavelmente por ter sido a explicação oferecida pelos setores de contabilidade aos membros das CIES.

A partir do que vem sendo compartilhando nas últimas reuniões da CIES, um tema gerador não seria justamente a dificuldade de gerenciamento do recurso financeiro, no sentido, da indefinição de como este recurso pode ser gasto? (Alice/CIESGrande Florianópolis).

Retratamos, em ambas as CIES, a grande dificuldade em utilizar os recursos financeiros des- tinados às ações de EPS por meio dos projetos elaborados conjuntamente a partir das necessidades sociais evidenciadas em âmbito local. Os participantes dos dois círculos de investigação tornam claro que os trâmites burocráticos para tal e a morosidade dos órgãos envolvidos nessa dinâmica dificultam o processo de trabalho das CIES. Essa lentidão significa, em outras palavras, manter paralisados projetos de EPS que são importantes socialmente, aguardando a liberação de recursos para contratar Instituições de Ensino Superior (IES) que possam executá-los.

O tema gerador que eu considero que precisaríamos discutir aqui na CIES é a 'indefinição de mecanismos burocráticos de utilização do recurso financeiro'. Porque o que o MS fez foi construir uma política, ele instituiu uma nova forma de liberação do financiamento [...]. Uma dificuldade geral é de 'como as CIES podem gastar estes recursos?'. A maioria das CIES já tem propostas de ações $e$ projetos, no entanto, não encontram mecanismos legais que garantam a utilização desse recurso [...]. Esse é um tema gerador importante, até porque nós precisamos oficializar, de forma escrita, esta nossa dificuldade (Mathias/CIES-Grande Florianópolis).

No processo de Desvelamento Crítico da Realidade exposto no Quadro 2, os participantes das CIES dividiram responsabilidades na tentativa gerenciar a definição orçamentária descentralizada para as SDR referentes a cada região. Esse momento ocorreu diferentemente em cada comissão, pois, na CIES Grande Florianópolis, os representantes dos gestores na comissão cobraram uma postura da CIR para definição da estrutura que se responsabilizaria pela gestão do recurso, sendo definida a $18^{\mathrm{a}} \mathrm{SDR}$. Ao final do ano, quando a SDR comunicou que não conseguiu realizar o processo licitatório, os membros novamente se organizaram para formalizar um documento entregue à CIR, relatando todo o processo desenvolvido, os contatos realizados e solicitando uma postura diferente da Comissão Intergestores Regional sobre a gestão do recurso para o ano de 2010.

Na CIES Carbonífera, o processo ocorreu por meio de reuniões de grupos de trabalho e da plenária da CIES desenvolvidas dentro da $21^{\text {a SDR, }}$ cobrando uma ação em relação ao processo de contratação de IES para realizar as ações de EPS definidas pela CIES. Este movimento de "pressão", aliado à articulação realizada junto a alguns gestores da CIR e ao gestor da 21 a GERSA, fez com que a $21^{\text {a }}$ SDR estudasse e encontrasse formas de realizar o processo licitatório a fim de 
Quadro 2. Aspectos relacionados à gestão dos recursos financeiros destinados pela PNEPS às CIES, dialogados nos círculos de investigação.

\begin{tabular}{|c|c|c|c|}
\hline \multicolumn{2}{|c|}{ CIES Grande Florianópolis } & \multicolumn{2}{|c|}{ CIES Carbonífera } \\
\hline \multicolumn{2}{|c|}{$\begin{array}{l}\text { Tema gerador: indefinição de mecanismos burocráticos legais } \\
\text { de utilização dos recursos financeiros destinados às ações de } \\
\text { EPS propostas pela CIES e dos valores destinados } \\
\text { especificamente para a manutenção da comissão. }\end{array}$} & \multicolumn{2}{|c|}{$\begin{array}{l}\text { Tema gerador: dificuldade de gestão dos recursos da } \\
\text { PNEPS destinados às ações de EPS elaboradas pela CIES. }\end{array}$} \\
\hline Codificação & $\begin{array}{c}\text { Decodificação } \\
\text { (Descrição da realidade) }\end{array}$ & Codificação & $\begin{array}{c}\text { Decodificação } \\
\text { (Descrição da realidade) }\end{array}$ \\
\hline $\begin{array}{l}\text { - necessidade de } \\
\text { orientação sobre as } \\
\text { formas legais de como o } \\
\text { recurso da EPS } \\
\text { descentralizado para a } \\
\text { SDR pode ser aplicado; } \\
\text { - limitado } \\
\text { conhecimento e } \\
\text { morosidade do órgão } \\
\text { designado para } \\
\text { administrar o recurso } \\
\text { financeiro; } \\
\text { - necessidade de maior } \\
\text { mobilização dos } \\
\text { membros da CIES } \\
\text { para exigir da CIR uma } \\
\text { posição mais enfática a } \\
\text { respeito da morosidade } \\
\text { do órgão responsável } \\
\text { pela gestão. }\end{array}$ & $\begin{array}{l}\text { - a CIES elaborou os projetos } \\
\text { previstos para } 2009 \text { em agosto- } \\
\text { setembro para que as atividades } \\
\text { iniciassem no mesmo ano. Mas } \\
\text { a CIES enfrentou dificuldades } \\
\text { na gestão dos recursos; } \\
\text { - indefinição da CIR sobre qual } \\
\text { órgão assumiria a gestão dos } \\
\text { recursos. Após definição, houve } \\
\text { morosidade no processo } \\
\text { administrativo-burocrático; } \\
\text { - o processo da CIES não foi } \\
\text { analisado em tempo pelo } \\
\text { jurídico da SDR e os valores } \\
\text { voltaram ao Fundo Estadual, } \\
\text { sendo gasto em } 2009 \text { apenas } \\
\text { uma pequena parcela do recurso, } \\
\text { com ações de EPS desenvolvidas } \\
\text { por compra direta. }\end{array}$ & $\begin{array}{l}\text { - necessidade de orientação } \\
\text { sobre as formas legais de } \\
\text { como o recurso da EPS } \\
\text { descentralizado para a SDR } \\
\text { pode ser aplicado; } \\
\text { - limitado conhecimento e } \\
\text { morosidade do órgão } \\
\text { designado para administrar o } \\
\text { recurso financeiro. }\end{array}$ & $\begin{array}{l}\text { - a CIES elaborou os projetos } \\
\text { previstos para } 2009 \text { em julho } \\
\text { para que as atividades } \\
\text { iniciassem no mesmo ano. } \\
\text { Mas a CIES enfrentou } \\
\text { dificuldades na gestão desses } \\
\text { recursos; } \\
\text { - houve reuniões de trabalho } \\
\text { da CIES junto à SDR para } \\
\text { enfatizar a necessidade de } \\
\text { definição de uma "forma de } \\
\text { contratação" de IES para } \\
\text { desenvolver as propostas; } \\
\text { - o responsável jurídico pela } \\
\text { liberação da forma de } \\
\text { contratação pediu demissão. } \\
\text { A nova pessoa responsável } \\
\text { demonstrou interesse, mas } \\
\text { enfrentou entraves } \\
\text { burocráticos. }\end{array}$ \\
\hline \multicolumn{2}{|c|}{ Desvelamento Crítico da Realidade } & \multicolumn{2}{|c|}{ Desvelamento Crítico da Realidade } \\
\hline \multirow{2}{*}{\multicolumn{2}{|c|}{$\begin{array}{l}\text { Proposta de mudança: solicitar a CIR que uma nova } \\
\text { estrutura assuma a gestão dos recursos no ano de 2010; } \\
\text { aumentar o envolvimento de todos os membros da CIES e } \\
\text { CIR para obter do órgão responsável mais atenção na gestão } \\
\text { dos recursos; caso a DEPS/DEP não assumir a ação de EPS } \\
\text { sobre gestão do recurso da PNEPS, a CIES precisará elaborar } \\
\text { uma capacitação urgente para os envolvidos. } \\
\text { Ação desenvolvida: divulgação no Fórum da EPS (atual CIES } \\
\text { Estadual) e em oficinas/seminários promovidos pela DEPS/ } \\
\text { DEP (2009) a dificuldade de gestão dos recursos financeiros } \\
\text { destinados às CIES pela PNEPS; foi entregue um documento } \\
\text { a CIR relatando dificuldades na gestão dos recursos, } \\
\text { solicitando uma posição mais enfática junto ao órgão } \\
\text { responsável pela gestão financeira na região. }\end{array}$}} & \multicolumn{2}{|c|}{$\begin{array}{l}\text { Proposta de mudança: solicitar a CIR que, em } 2010 \text { uma } \\
\text { nova estrutura assuma a gestão dos recursos referente ao ano } \\
\text { de } 2009 \text {, analisando a possibilidade de algum município da } \\
\text { região assumir esse recurso fundo-a-fundo. }\end{array}$} \\
\hline & & \multicolumn{2}{|c|}{$\begin{array}{l}\text { Ação desenvolvida: divulgação no Fórum da EPS (atual CIES } \\
\text { Estadual) e em oficinas/seminários promovidos pela DEPS/ } \\
\text { DEP (2009) a dificuldade de gestão dos recursos financeiros } \\
\text { destinados às CIES pela PNEPS; Membros da CIES } \\
\text { mobilizaram os gestores para intervir junto a } 21^{\text {a }} \text { SDR a fim } \\
\text { agilizar o processo de análise para definição de contratação de } \\
\text { IES. Após intervenção, a SDR lançou o edital de tomada de } \\
\text { preço. A IES ganhadora desenvolveu ações em } 2010 \text { e foi } \\
\text { acompanhada por uma comissão de fiscalização formada por } \\
\text { membros da CIES que não tinham envolvimento com IES e } \\
\text { por funcionários da SDR. }\end{array}$} \\
\hline
\end{tabular}

contratar a IES que começaria as ações de EPS previstas para a região no início do ano de 2010.

$\mathrm{Na}$ última reunião acompanhada pela pesquisadora-mediadora, em dezembro de 2009, em cada uma das CIES e após um processo de avaliação pessoal, os participantes analisaram as ações desenvolvidas e estabeleceram uma agenda de ações com propostas de mudanças que seriam imple- 
mentadas ao longo do ano 2010. A atitude de mudança ${ }^{15}$ decorrente da realidade problematizada retrata a transformação dos membros das CIES ao longo da IT, pois, no contexto da educação libertadora, cada pessoa e grupo têm seu tempo no processo de conscientização, que é dialético nas ações políticas e pedagógicas. O tempo para a reflexão sobre os temas geradores, o despertar para atuar frente às problemáticas na práxis coletiva, $\mathrm{o}$ esforço dos sujeitos pelo diálogo, possibilita que interfiram sobre realidade a ser transformada ${ }^{12-14}$.

Um aspecto que merece atenção foi que efetivamente a CIES Carbonífera conseguiu empenhar os recursos 2007/2008, evitando que estes retornassem ao Fundo Estadual de Saúde. A contratação foi efetuada por processo de licitação (pregão), vencida pela IES inscrita com o valor mais baixo. Essa forma de contratação despertou reflexão por parte da CIES, como é ilustrado no relato a seguir.

A nova advogada conversou com o gerente e o secretário da SDR para que fossem escolhidas Universidades da região, priorizando assim o conhecimento, monitores, atores sociais da própria região. Elaborou-se um ofício [...] mas a SES não liberou. Logo, teremos que correr o processo na forma de pregão, sendo que, desse modo, instituições de todo o Brasil podem concorrer, vencendo a de menor preço. [...] Consideramos isso perigoso, pois não adianta instituições que não conhecem a nossa realidade vir aplicar uma ação de EPS para nós, como já falamos em outro momento, isso vai contra a própria lógica da regionalização tão discutida na PNEPS (Margarete/CIES-Carbonífera).

Assim, após muitas discussões e trabalho, a CIES Carbonífera, no início de dezembro de 2009, por meio de licitação, contratou uma IES de sua região que ganhou o processo licitatório e se responsabilizou pela elaboração e desenvolvimento dos projetos de EPS a partir da proposta definida pela CIES no edital de seleção. Desse modo, as atividades puderam ser iniciadas nos primeiros meses de 2010 e acompanhadas e avaliadas pela comissão de fiscalização e avaliação da CIES.

De fato, a Política Nacional de Educação Permanente em Saúde preconiza que sejam consideradas as especificidades regionais para a superação das desigualdades, bem como o aproveitamento da capacidade já instalada na região - no caso, as Universidades que têm cursos na área da saúde - de oferta institucional de ações formais de educação na saúde ${ }^{2}$, o que reflete a coerência da análise reflexiva realizada pelo círculo de investigação da CIES Carbonífera, sobre a forma de contratação para realizar as ações de EPS.
Mesmo frente a tantas dificuldades, a CIES Carbonífera sinalizou avanços no sentido de acompanhamento e avaliação das ações de EPS. Estudos apontam que as estratégias de ação da PNEPS praticamente não contam com sistemas de monitoramento e avaliação das atividades e projetos. Inclusive, alguns locais, não têm acesso aos mecanismos de acompanhamento de execução dos projetos, sendo que isso não faz parte das atividades rotineiras ${ }^{6}$.

[...] a Comissão de Fiscalização e Avaliação para acompanhar as ações da IES vencedora já foi montada na última reunião da CIES, sendo que os participantes não têm envolvimento com nenhuma das IES da região [...]. Os nomes devem ser entregues na SDR para que façam a Portaria de nomeação depois da licitação (Café/CIES-Carbonífera).

A ausência de mecanismos de monitoramento e avaliação em nível local pode comprometer o compromisso das CIES com o sistema de saú$\mathrm{de}^{6}$. Ainda, a proposta de descentralização e pactuação local acaba sendo atravessada pelo mecanismo centralizado de liberação dos recursos, o que pode gerar atrasos importantes à execução das atividades programadas. As etapas de codificação e decodificação realizadas pelos círculos de investigação indicaram grande dificuldade relacionada à utilização dos recursos.

A nossa preocupação é de que o CGR [atual CIR] compreenda que a CIES está fazendo o que cabe a nós fazer, só que estamos enfrentando um momento de indefinição sobre que estrutura irá administrar o nosso recurso financeiro, se é a SDR ou se é a Associação dos Municípios. Isso é um problema atualmente para nós [...]. Poderíamos ter iniciado um curso no mês passado, pois o projeto já está pronto desde agosto, no entanto, o curso não começou devido a essa indefinição, sendo que cabe ao CGR [atual CIR] decidir (Sueli/CIESGrande Florianópolis).

$\mathrm{O}$ excesso de burocracia e de indefinições permeia a atividade das estruturas regionais no processo de Educação Permanente em Saúde em Santa Catarina, o que exige paciência e tempo por parte dos membros das CIES. Um aspecto problematizado no interior dos círculos de investigação foi sobre a necessidade que a estrutura pública tem de burocratização devido à falta de "transparência pública" que ainda é uma realidade em nosso país. Retratam-se nas CIES enfrentamentos políticos acerca do processo de gestão, justificando-se a excessiva burocratização por problemas relacionados a desvios de conduta no serviço público.

Há uma imensa burocratização que atrapalha significativamente os processos, mas é a única for- 
ma de evitar, ou melhor, de dificultar os desvios que muitas vezes ocorrem nos recursos públicos. Dessa forma os honestos pagam pelas atitudes dos desonestos, pois muitas vezes os recursos voltam para os cofres da união, visto que não se conseguiu a tempo desatrelar todas as estruturas burocráticas para a utilização dos mesmos (Paulo/CIESGrande Florianópolis).

A descentralização do financiamento da PNEPS, cuja responsabilidade é compartilhada, enfrenta dificuldades agravadas pelo fato de que as diferentes instâncias do SUS produziram mecanismos ágeis para o financiamento e contratação de ações e serviços de saúde, mas não para ações e serviços educacionais. Assim, toda a máquina pública, que opera bem em âmbito das ações de saúde, "emperra" quando se trata de ações de educação. Além disso, há necessidade de se criar mecanismos participativos de avaliação e controle para um exercício responsável e autônomo na gestão local ${ }^{19}$, pois tais mecanismos auxiliam a coibir possíveis desvios de conduta, proporcionando uma transparência pública na gestão dos recursos.

Outro aspecto abordado nos círculos de IT refere-se à necessidade de compreender a PNEPS, não apenas como uma proposta do MS, mas como um referencial teórico-metodológico para as ações que envolvam trabalho e educação no SUS. É de conhecimento que as "políticas são objetos de disputa e, nas trocas de governo, são submetidas à barganha, ao desvirtuamento, à substituição" ${ }^{20}$, fato que deveria ser trabalhado de forma distinta em relação a essa política. Deve-se destacar também que, como no SUS há autonomia em cada esfera de gestão, mesmo que, em âmbito federal uma política "perca força" - no sentido de diminuição de recursos, nada impede que em âmbito estadual e/ou municipal se produzam iniciativas criativas para manter o ritmo de efetivação de uma política considerada prioritária.

A busca por respostas, no interior dos círculos de investigação, leva a crer na necessidade de estabelecer um processo educativo com os próprios envolvidos nas estruturas de planejamento regional da PNEPS, já que ela deve ser feita a partir dos problemas enfrentados na realidade e leva em consideração os conhecimentos e as experiências que as pessoas possuem. A EPS, segundo a PNEPS, é aprendizagem no trabalho, de modo que o aprender e o ensinar se incorporam ao cotidiano das organizações e ao trabalho ${ }^{2}$, tendo como objetivo a transformação das práticas profissionais e da própria organização da atividade laboral.
Minha sugestão é que a nossa articuladora solicite um ponto de pauta na reunião do Fórum de EPS [atual CIES Estadual] a fim de analisarmos se mais alguma CIES no Estado está vivenciando esse problema. Caso seja um problema comum para outras comissões, solicitar que a DEPS/DEP desenvolva uma ação de EPS, de modo que expliquem como os recursos financeiros destinados pela PNEPS às CIES possam ser administrados (Stella/CIESGrande Florianópolis).

A partir do momento que as articuladoras das CIES participantes do estudo levaram a problemática para o Fórum de EPS [atual CIES Estadual], foi constatado que a maioria das CIES no Estado estava enfrentando essa dificuldade, o que promoveu a inclusão do tema gerador lavantado pelas CIES Grande Florianópolis e Carbonífera como uma das necessidades prioritárias que deveriam ser desenvolvidas no Plano Estadual de Educação Permanente em Saúde no ano de 2010.

Nesse aspecto, retratamos a importância do compartilhamento de saberes por meio do diálogo e da produção de alteridade que o debate no coletivo propiciou nesse estudo, ambos indispensáveis para a transformação da realidade e busca de soluções relativas à gestão de recursos financeiros da PNEPS, visto que a burocratização dos procedimentos administrativos para efetivação das atividades se mantém. Importantíssimo entrar em contato com outros pontos de vista, importantíssimo que se "produzam incômodos" a partir dessa reflexão, porque as mudanças só são efetivadas quando fazem sentido para os sujeitos implicados. Destacamos que, implicado no processo de conhecer está a tarefa de intervir. Intervir para a libertação, para a transformação das condições injustas, de vida e de saúde ${ }^{13}$.

Tendo em vista que a EPS constitui-se em estratégia fundamental às transformações do trabalho na área da saúde, faz-se necessário criar permeabilidade para processos participativos de reflexão, que propiciam a estruturação de trabalhadores comprometidos e tecnicamente preparados para atuar no setor. A proposta teóricometodológica da EPS é descentralizar e disseminar a capacidade pedagógica aos próprios trabalhadores do setor, aos gestores e ao controle social, de modo que o SUS seja percebido verdadeiramente como uma rede ensino-serviço, sendo esse outro importante desafio a ser superado ${ }^{20}$. Por conta destas características, as ações de educação permanente em saúde precisam ser efetivadas também no cotidiano do trabalho (e não somente em momentos de capacitação), envolvendo tra- 
balhadores da saúde e controle social (e não somente docentes das instituições de ensino).

Compreender as formalidades do processo de gestão que cabe as CIR e as CIES é fundamental para o financiamento dos projetos e para o bom andamento das atividades, mas não deveria ser a única preocupação. Longe do que vem acontecendo, o foco das CIES deveria ser a ruptura com a lógica da compra e pagamento de produtos e procedimentos educacionais baseados na oferta existente de serviços educacionais². Ao contrário, deveria se fortalecer a capacidade de demandar e efetivar mudanças e melhorias institucionais baseadas na análise dos processos de trabalho, nos seus problemas e desafios.

As diferentes CIES estão perdendo um tempo 'sagrado' tentando achar uma forma junto às diferentes estruturas que estão administrando esses recursos, para gastar esse dinheiro sem ter problemas com a Lei de Responsabilidade Fiscal (Mathias/CIES-Grande Florianópolis).

As propostas de mudanças e as ações já desenvolvidas durante a Investigação Temática são reflexos do interesse das CIES estudadas em mudar a realidade vivenciada, que lhes parece incômoda. Esse desconforto retrata uma nova visão de mundo, conferida provavelmente pelo diálogo coletivo, troca de saberes e empenho dos membros em leituras e estudo durante o processo da IT. Esse processo é considerado uma "tomada de consciência" da realidade com posterior intervenção, que somente ocorre se permeado por um processo de conscientização ${ }^{14}$.

\section{Conclusões}

As CIES têm realizado um trabalho fundamental e desafiador do ponto de vista técnico, que merece atenção e destaque em âmbito da pesquisa científica. Os recentes dispositivos de gestão descentralizada, por meio do Pacto pela Saúde, tornam-se interessantes à medida que conferem autonomia a esses representantes para legitimar necessidades regionais em saúde, ao passo que exigem responsabilidade e capacidade técnica, abertura ao diálogo e uma boa dose de tolerância frente às adversidades.

Este estudo não se pretendeu exaustivo, mas, sim, buscou apenas despertar reflexões e diálogos na interface formação-gestão-trabalho do
SUS, desenvolvidos pelos próprios sujeitos sociais do processo, em que a gestão de recursos financeiros ainda se configura como um desafio a ser superado na realidade da educação permanente em saúde, pois não há como manter uma ação continuada de processos de mudança se os aspectos relativos ao financiamento ainda se configuram como um entrave.

As duas realidades investigadas vivem problemáticas semelhantes em relação à gestão de recursos. Possivelmente essas sejam situações vivenciadas por outras CIES no próprio Estado de Santa Catarina e no Brasil. As CIES estudadas conseguiram apontar esse tema como um aspecto urgente a ser trabalhado no Plano Estadual de EPS. Talvez devido à mudança na lógica de transferências de recursos federais vivenciada no período da investigação, atendendo à heterogeneidade dos municípios brasileiros e às particularidades regionais ${ }^{7}$, a problemática seja ultrapassada e minimizada com o tempo, abrindo espaço para avanços no movimento de descentralização político-administrativa e para a progressiva transferência de responsabilidades pela execução de ações em EPS aos Estados e Municípios. Isso é o que esperamos.

\section{Colaboradores}

F Ferraz, VMS Backes, FJ Mercado-Martinez, LCM Feuerwerker e MM Lino participaram igualmente de todas as etapas de elaboração do artigo.

\section{Agradecimentos}

Ao Grupo de Pesquisa em Educação em Enfermagem e Saúde (EDEN/PEN/UFSC), exemplo concreto de construção de conhecimentos a partir de processos de ensino-aprendizagem compartilhados. Ao CNPq, pelo auxílio financeiro por meio de uma bolsa de doutorado no período de realização deste estudo. 


\section{Referências}

1. Brasil. Portaria GM/MS no 1.996 , de 20 de agosto de 2007. Dispõe sobre as diretrizes para a implementação da Política Nacional de Educação Permanente em Saúde e dá outras providências. Diário Oficial da União 2007; 22 ago.

2. Brasil. Ministério da Saúde (MS). Secretaria de Gestão do Trabalho e da Educação na Saúde. Política Nacional de Educação Permanente em Saúde. Brasília: MS; 2009.

3. Brasil. Decreto no 7.508 , de 28 de junho de 2011. Regulamenta a Lei no 8.080 , de 19 de setembro de 1990, para dispor sobre a organização do Sistema Único de Saúde-SUS, o planejamento da saúde, a assistência à saúde e a articulação interfederativa, e dá outras providências. Diário Oficial da União 2011; 29 jun.

4. Feuerwerker LCM. Modelos tecnoassistenciais, gestão e organização do trabalho em saúde: nada é indiferente no processo de luta para a consolidação do SUS. Interface Comun Saúde Educ 2005; 9(18): 489-506.

5. Ugá MA, Piola SF, Porto SM, Vianna SM. Descentralização e alocação de recursos no âmbito do Sistema Único de Saúde (SUS). Cien Saude Colet 2003; 8(2):417-437.

6. Campos FE, Pierantoni CR, Haddad AE, Viana ALA, Faria RMB. Os desafios atuais para a educação permanente no SUS. Cad. RH Saúde 2006; 3(1):39-51.

7. Castro ALB, Machado CV. A política de atenção primária à saúde no Brasil: notas sobre a regulação e o financiamento federal. Cad Saude Publica 2010; 26(4):693-705.

8. Santa Catarina. Secretaria de Estado da Saúde (SES). Comissão Intergestores Bipartite (CIB). Deliberação 225/CIB/2007, de 17 de dezembro de 2007. Define que as Comissões Permanentes de Integração Ensino-Serviço atenderão os municípios de acordo com a lógica da regionalização do estado, de forma que nenhum municipio, assim como nenhum Colegiado de Gestão Regional - CGR, fique sem sua referência a uma Comissão Permanente de Integração Ensino-Serviço. Florianópolis: CIB; 2007.

9. Santa Catarina. Secretaria de Estado de Saúde (SES). Comissão Intergestores Bipartite (CIB). Santa Catarina. Deliberação 205/CIB/09 de 10 de dezembro de 2009. Define a constituição do Colegiado de Gestão Regional - CGR Extremo Oeste - 03, composto pela Região de Saúde formada pelos municípios das Secretarias de Desenvolvimento Regional de São Lourenço do Oeste e Xanxerê, resultando no $16^{\circ}$ CGR no Estado de Santa Catarina. Florianópolis: CIB; 2009.
10. Ceccim RB, Feuerwerker LCM. O quadrilátero da formação para a área da saúde: ensino, gestão, atenção e controle social. Physis 2004; 14(1):41-65.

11. Ceccim RB. Educação Permanente em Saúde: desafio ambicioso e necessário. Interface Comun Saúde Educ 2005; 9(16):161-168.

12. Freire P. Pedagogia do Oprimido. $41^{\text {a }}$ Edição. Rio de Janeiro: Paz e Terra; 2005.

13. Freire P. Educação como prática da liberdade. $30^{\mathrm{a}}$ Edição. Rio de Janeiro: Paz e Terra; 2007.

14. Freire P. Extensão ou Comunicação. 13a Edição. Rio de Janeiro: Paz e Terra; 2006.

15. Demo P. Elementos Metodológicos da Pesquisa Participante. In: Brandão CR, organizador. Repensando a Pesquisa Participante. $3^{a}$ Edição. São Paulo: Brasiliense; 1987. p. 104-130.

16. Saupe R, Brito VH, Giorgi MDM. Utilizando as concepções do educador Paulo Freire no pensar e agir da Enfermagem. In: Saupe R, organizadora. Educação em Enfermagem: da realidade construída à possibilidade em construção. Florianópolis: Editora da UFSC; 1998. p. 244-272.

17. Brasil. Ministério da Saúde(MS). Conselho Nacional de Saúde. Resolução nº 196 de 10 de outubro de 1996. Diretrizes e Normas Regulamentadoras de Pesquisas Envolvendo Seres Humanos. Diário Oficial da União 1996; 16 out.

18. Santa Catarina. Secretaria de Estado da Saúde (SES). Comissão Intergestores Bipartide. Deliberação $n^{\circ}$ 248/ CIB/2008. Florianópolis: SES; 2008.

19. Arretche M. Financiamento federal e gestão local de políticas sociais: o difícil equilíbrio entre regulação, responsabilidade e autonomia. Cien Saude Colet 2003; 8(2):331-345.

20. Ceccim RB. Educação Permanente em Saúde: descentralização e disseminação de capacidade pedagógica na saúde. Cien Saude Colet 2005; 10(4):975986.

Artigo apresentado em 01/03/2012

Aprovado em 10/07/2012

Versão final apresentada em 06/08/2012 
